\title{
Práxis colaborativa no processo de investigação em rede: o debate metodológico sobre a abordagem qualitativa
}

\author{
Elsieni Coelho da Silva ${ }^{1}$ \\ Antônio Neto Ferreira dos Santos ${ }^{2}$ \\ Graciela María Elena Fernández ${ }^{3}$
}

\begin{abstract}
RESUMO
A práxis de pesquisas colaborativas da Rede de Pesquisadores do CentroOeste possibilitam a apreciação de coleta de dados em teses e dissertações e a elaboração de diferentes recortes, análises, debates e comunicações sobre professor relacionadas com a produção acadêmica dos programas de pós-graduação em educação dessa região. Em um desses contornos, questiona-se: o que revelam os dados quantitativos e qualitativos sobre abordagem de pesquisa em teses e dissertações sobre professor no CentroOeste? Como eles contribuem para pensar e diferenciar abordagem qualitativa no método fenomenológico e materialista histórico-dialético? $\mathrm{O}$ propósito é analisar essas abordagens para aperfeiçoar a construção de referenciais teórico-metodológicos, sobretudo, ampliar a interlocução de metaanálises suprindo carências de quem busca a pesquisa colaborativa como meio de formação. Infere-se que a pesquisa colaborativa amplia processos de formação e conscientização, o que torna presente uma atitude crítico-reflexiva entre pesquisadores na construção de conhecimentos sistematizados.
\end{abstract}

PALAVRAS-CHAVE: Abordagem qualitativa. Pesquisa colaborativa. Formação docente. Método fenomenológico. Método materialista histórico Dialético.

\footnotetext{
1 Doutora em Educação. Universidade Federal de Uberlândia, Uberlândia, Minas Gerais, Brasil. Orcid. https://orcid.org/0000-0002-4483-0765. E-mail: elsienicoelho@ufu.br.

2 Doutor em Educação. Universidade Federal de Uberlândia, Uberlândia, Minas Gerais, Brasil. Orcid. https://orcid.org/0000-0002-6255-6077.E-mail: antonioneto@ufu.br.

${ }^{3}$ Mestra em Educação. Docente del Departamento de Educación e investigadora del Núcleo de Estudios Educacionales y Sociales (NEES) de la Facultad de Ciencias Humanas de la Universidad Nacional del Centro de la Provincia de Buenos Aires. Tandil - Argentina. Orcid: https://orcid.org/0000-0002-4526-227X. E-mail: grafe@ @fch.unicen.edu.ar.
} 
Collaborative praxis in the process of network research: the methodological debate on the qualitative approach 4

\begin{abstract}
The praxis of collaborative research of the Center-West Researchers Network enables the assessment of data collection in doctoral and master theses and the elaboration of different clippings, analyses, debates, and communications on professors related to the academic production of postgraduate programs in education in this region. In one of these outlines, it is questioned: what do the quantitative and qualitative data on the research approach in theses and dissertations on professors in the center-west reveal? How do they contribute to thinking and differentiating qualitative approach in the phenomenological and historical-dialectical materialist method? The purpose is to analyze these approaches to improve the construction of theoretical-methodological references, mainly, to broaden the interlocution of meta-analyses, filling the needs of those who seek collaborative research as a means of formation. It is inferred that collaborative research expands formation and awareness processes, which brings about a critical-reflective attitude among researchers in the construction of systematized knowledge.
\end{abstract}

KEYWORDS: Qualitative approach. Collaborative research. Teacher formation. Phenomenological method. Historical-dialectical materialist method.

Praxis colaborativa en el proceso de investigación en red: el debate metodológico sobre el enfoque cualitativo ${ }^{5}$

\title{
RESUMEN
}

La práctica de investigaciones colaborativas de la Red de Investigadores del Centro-Oeste posibilita la apreciación de recolección de datos en tesis y disertaciones y la elaboración de diferentes recortes, análisis, debates y comunicaciones sobre profesor relacionadas con la producción académica de los programas de posgrado en educación de esa región. En uno de esos contornos, se pregunta: ¿qué revelan los datos cuantitativos y cualitativos sobre abordaje de investigación en tesis y disertaciones sobre profesor en

\footnotetext{
${ }^{4}$ Tradução Pietro Fernandes Coelho Santos. E-mail: pietro.fcs@ gmail.com.

${ }^{5}$ Tradução Pietro Fernandes Coelho Santos. E-mail: pietro.fcs@ gmail.com. 
el Centro-Oeste? ¿Cómo contribuyen a pensar y diferenciar enfoque cualitativo en el método fenomenológico y materialista históricodialéctico? El propósito es analizar estos enfoques para perfeccionar la construcción de referenciales teórico-metodológicos, sobre todo, para ampliar la interlocución de los metaanálisis, satisfaciendo las necesidades de quien buscan la investigación colaborativa como medio de formación. Se infiere que la investigación colaborativa amplía los procesos de formación y concientización, lo que genera una actitud crítico-reflexiva entre los investigadores en la construcción del conocimiento sistematizado.

PALABRAS CLAVE: Abordaje cualitativo; Investigación colaborativa; Formación docente; Método fenomenológico; Método materialista histórico dialéctico.

$$
* * *
$$

\section{Introdução}

A rede de pesquisadores do Centro-Oeste - REDECENTRO ${ }^{6}$ caracterizase como uma atividade cooperativa de investigação e estratégias de formação de pesquisadores e de docente, em diferentes níveis formativos, com o intuito de enfrentar os desafios da produção de conhecimento, especialmente na construção de caminhos teórico-metodológicos plausíveis e coerentes.

Ela foi concebida a partir de um projeto interinstitucional e é composta de docentes orientadores, pesquisadores, doutorandos, mestrandos e bolsistas de projeto de iniciação científica articulada para a composição de uma pesquisa colaborativa em rede. Conceitualmente, como descrito por Magalhães (2021, s/p), deve ser associada à ideia de cooperação, como

[...] prática imprescindível entre pesquisadores(as) frente ao trabalho coletivo que se propõem na construção de conhecimentos [...] a pesquisa colaborativa tem se mostrado como uma experiência potente no campo da pesquisa em educação, dos quais destacamos alguns aspectos: [...] porque investe numa dupla

\footnotetext{
${ }^{6}$ A REDECENTRO reúne pesquisadores interessados em docentes da região Centro-Oeste. Foi articulada pelas universidades: de Brasília (UNB), Federal de Goiás (UFG), Federal de Mato Grosso (UFMT), Federal de Mato Grosso do Sul (UFMS), Federal do Tocantins (UFT), Federal de Uberlândia (UFU) e Universidade de Uberaba (UNIUBE), na pesquisa A produção acadêmica sobre professores(as): estudo interinstitucional da região Centro-Oeste.
} 
responsabilidade indissociável - criar as melhores condições de trabalho e ampliar a capacidade de desenvolver ações para promover aos (às) pesquisadores(as), apoio no desenvolvimento profissional; sustenta possibilidades de conjunção de pesquisadores(as) e grupos de pesquisadores(as), numa perspectiva ulti/inter/transdisciplinar, [...] amplia o espaço para debate e as possibilidades de aprender.

Dessa forma, a pesquisa colaborativa e em rede sustenta um projeto de colaboração que é susceptível de "motivar os(as) pesquisadores(as) para aprofundamento de estudos, e isso ajuda a consolidar um caráter conceitualmetodológico e epistemológico, no âmbito da pesquisa em educação" (MAGALHÃES, 2021, s/p). Essa concepção sustenta o mapeamento e a análise de teses e dissertações (T/D) sobre a temática - professores dos programas de pós-graduação da região Centro-Oeste em educação, além de ter mantido o foco do grupo e o aperfeiçoamento da práxis colaborativa. Como afirmam Magalhães, Souza e Argüello (2021, s/p)

A importância da investigação colaborativa e em rede se destaca por suas exigências imediatamente coletivas: capacitar no que se refere aos princípios teórico, epistemológico, gnosiológico, ontológico, metodológico, político e ideológico, e relacional, que influem nas subjetividades, linguagens, saberes, conhecimentos, relações profissionais, mas também, e sobretudo, na capacidade metacognitiva e na vigilância epistemológica de cada pesquisador(a) no próprio processo da pesquisa.

Assim, a REDECENTRO, portanto, foi criada a partir dessa estrutura investigativa e colaborativa que se pensa formativa de seus pesquisadores. Prioriza-se, assim, a defesa de bases teórico-metodológicas essenciais para o desenvolvimento de pesquisa como práxis, o que envolve: i) parcerias nacionais e internacionais, negociação e interação; ii) responsabilidade e engajamento; iii) coparticipação e autonomia; iv) inclusão ativa de seus participantes nas diferentes etapas da construção do conhecimento. Esse último envolve: a) reuniões técnicas e reflexivas; b) coleta e estruturação de banco de dados; c) estudos, debates, análises e socialização de resultados. Formando-se assim um ambiente propício à troca de experiências e colaboração (FRANCO; MOROSINI, 2001). 
Desde esse ponto de vista, os integrantes da REDECENTRO têm sistematicamente se dedicado à realização de meta análises dos trabalhos acadêmicos sobre os professores, no período 1999-2014, dos Programas de Pós-Graduação em Educação (PPGE) constituintes da rede. Emerge, então, um posicionamento que exige do pesquisador uma definição clara e fundamentada quanto ao método, o qual sustenta a lógica da produção de conhecimento, que no nosso caso é, sobretudo o enfoque do materialismo histórico-dialético (MHD).

O interesse pelo professor e seu universo de atuação como objetos de investigação sistemática se projetou de tal modo que o volume de trabalhos resultantes de pesquisas de pós-graduação em educação compôs um corpus de dados útil para entender coletivamente o processo dessa produção intelectual (SOUZA; MAGALHAES, 2018), culminando numa práxis colaborativa.

Resultado de práticas dialogadas na Rede, este texto faz parte do aprimoramento reflexivo dessa produção investigativa. Igualmente, como parte de construção de material formativo, ele parte das seguintes indagações: o que revelam os dados quantitativos e qualitativos sobre abordagem de pesquisa em T/D sobre professor no Centro-Oeste? Como eles contribuem para pensar e diferenciar abordagem qualitativa em dois métodos distintos: o método fenomenológico e o materialista histórico-dialético? Como a pesquisa apoia e consolida a pesquisa colaborativa e em rede desenvolvida pela REDECENTRO. Essas perguntas guiam o levantamento de dados documentais e a análise da produção acadêmica, mas sobretudo apoia a construção de referenciais teóricometodológicos para o avanço das pesquisas que o grupo se propõe realizar.

Utilizar-se-á de meta-análise para conhecer, entender e construir possíveis caminhos metodológicos para suprir certas carências de quem busca a colaboração como meio de formação, de modo a anular os desvios do percurso investigativo escolhido. Uma constatação derivada da leitura de trabalhos, cujo processo de produção, muitas vezes, mostra-se frágil metodologicamente ante a complexidade do registro da construção de conhecimentos. Parece 
faltar uma construção teórico-metodológica que fundamente e justifique a opção pela metodologia adotada, que em sua maior parte permanece implícita.

Uma realidade resultante da falta consensual quanto à necessidade de explicitar, em detalhe, os caminhos metodológicos seguidos no desenvolvimento de T/D. Mas que, no grupo da REDECENTRO, como uma concepção coletiva, acredita-se que um pós-graduando consciente dos fundamentos teórico-metodológicos de sua atividade acadêmica é condição sine qua non para produzir conhecimentos mais consistentes. Ainda que esses fiquem subjacentes à materialização escrita da pesquisa.

Como dizem Bogdan e Biklen (1994, p. 52), explícita ou não, consciente ou não, toda investigação sistemática revela uma tendência teórica, um modo de construir conhecimento, um paradigma que "consiste num conjunto aberto de asserções, conceitos ou proposições logicamente relacionadas e que orientam o pensamento a investigação". Considera-se que essa afirmação pretende expor que o processo de transformar dados em resultados por meio de análises interpretativas na elaboração de conhecimentos supõe coerência; e essa depende de uma escolha feita com consciência metodológica, epistemológica e teórica, com a experiência das vivências associadas com o ato de pesquisar, ou seja, de uma lógica racional.

Se assim o for, tal coerência não pode ser secundarizada em detrimento de elementos circundantes do objeto investigado. Necessariamente, a produção intelectual científica demanda do pósgraduando coerência entre a atitude de ser e estar em situações-problema; nas formas de se posicionar perante o objeto de estudo e a concepção de construção do conhecimento; e na escolha do método - fundamental para definir tais formas em prol de uma produção científica consistente. Por isso, o pesquisador deve ser incitado a conhecer métodos e a saber escolhê-los. A escolha é passo elementar da sustentação de uma tentativa de construir e sistematizar conhecimentos, pois a metodologia vai além da ideia de técnica instrumental referente a "processos de coleta, registro, organização, sistematização e tratamento de dados e informações" (GAMBOA, 2013, p. 
69). Ela se refere às bases teóricas, isto é, aos núcleos conceituais básicos, os autores e clássicos no mapeamento e debate sobre o assunto e epistemologias que se referem "aos critérios de 'cientificidade', como concepções da ciência, dos requisitos da prova ou da validez, da casualidade etc." (GAMBOA, 2013, p. 69) e que uma pesquisa sistemática precisa ter.

Na construção de um referencial teórico-metodológico útil para fundamentar coerentemente uma investigação, a abordagem da pesquisa constitui como um dos recortes a serem analisados a partir de dados coletados por múltiplos pesquisadores da Rede com o uso da "ficha de análise" (SOUZA; MAGALHÃES; QUEIROZ, 2017, p. 217-31), "[...] que os pesquisadores construíram, apresentaram e aperfeiçoaram em conjunto; isto é, em reuniões técnicas, seminários e estudos teóricometodológicos" (SILVA; SANTOS, 2017, p. 77-8).

As fichas, como fontes documentais secundárias de pesquisa, possibilitaram a tabulação de dados quantitativos, os quais traduzem tendências de abordagem e referenciais, nas T/D, conforme opções metodológicas dos autores. Os dados qualitativos, em análise, referem-se a excertos de concepções e guias teóricos, que revelam coerências, contradições e desafios da produção. Essa opção exigiu uma revisão dos parâmetros teóricometodológica a que os autores recorreram ${ }^{7}$.

Então, do corpus de 77 trabalhos, que representam 10\% da totalidade de estudos sobre professor defendidos e cadastrados no repositório de seis programas de pós-graduação de 1999 a 2014 apenas 46 foram analisados para desenvolver este estudo. Uma seleção justificada pelo fato da inclusão do indicador de abordagem da pesquisa, numa atualização da "ficha" usada como instrumental padrão pela REDECENTRO, apenas para a produção de 2006 a 2014. Os dados coletados são relativos ao tipo de abordagem (qualitativa, quantitativa, quali/quanti, multirreferencial) e referencial teórico, além de

\footnotetext{
${ }^{7}$ Uma primeira análise foi desenvolvida e publicada por SILVA, E. C.; SANTOS, A. F. Desafios epistemológicos e metodológicos da abordagem qualitativa de pesquisa. In: SOUZA, R. C. C.; MAGALÃES, S. O. (org.) Epistemologia da práxis e epistemologia da prática: repercussões na produção de conhecimento sobre professores. Campinas, SP: Mercado de Letras, 2018. p. 65-94.
} 
incluir extratos das T/D que evidenciam a escolha da abordagem e citações teórico-conceituais pelos autores.

Nas referências, dois problemas se destacam: a superação instrumental e a coerência teórico-metodológica, que se relacionam diretamente com a produção de conhecimento. Esses problemas precisam ser enfrentados e debatidos em prol do aperfeiçoamento do ato de pesquisar. Mesmo que o mapeamento e a discussão neste estudo recortem a abordagem de pesquisa, essas têm relações intrínsecas com o método, o que aponta outras associações com os tipos de pesquisa e os procedimentos.

A discussão teórica da abordagem da pesquisa se centra nas bases epistemológicas e instrumentais, com ênfase numa dicotomia, coexistência ou uma unidade entre a abordagem quantitativa e a abordagem qualitativa, que incorporam as pesquisas educacionais. Tais bases vêm de estudos de Gamboa (2013), Lüdke e André (1986), Chizzotti (1991), Triviños (1987) e Bogdan e Biklen (1994). Mas há que considerar as nuanças e os fundamentos de uma abordagem específica. O mapeamento quantitativo do tipo de abordagem e dos referenciais, nas fontes documentais bibliográficas aqui consideradas, permite revelar tendências de abordagem e ideário, enquanto os excertos se abrem a uma análise qualitativa das fundamentações e dos desafios.

\section{Abordagens de pesquisa: tipos e referenciais teóricos}

O mapeamento quantitativo quanto ao tipo de abordagem de pesquisa, quantitativa, multirreferencial, qualitativa e mista, conforme tabela 1 , revela que $87 \%$ se valem da abordagem qualitativa explicitada ou não.

TABELA 1. Tipo de abordagem apresentados nas T/D.

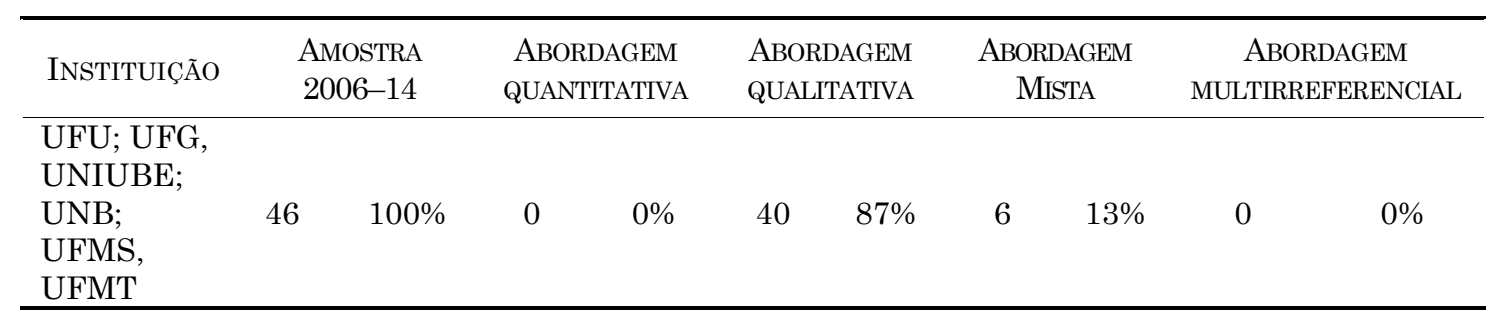

Fonte: dados da pesquisa REDECENTRO (SANTOS; SILVA, 2018). 
Historicamente a abordagem qualitativa foi incluída nas pesquisas educacionais nos anos 1960, na Europa e estados Unidos (BOGDAN; BIKLEN, 1994) e no Brasil, na década de 80 (GATTI e ANDRÉ, 2010; GAMBOA; SANTOS FILHO, 2013). Como abordagem que predominante nas T/D sobre o professor, em alguns casos, o autor se ocupa apenas de anunciála; em outros casos, há esforços para caracterizá-la.

O gráfico, a seguir, mostra doze autores mais citados em estudos, sem distinção do tipo de abordagem, seja qualitativa, quantitativa ou mista.

GRÁFICO 1. Referenciais sobre abordagem nas T/D

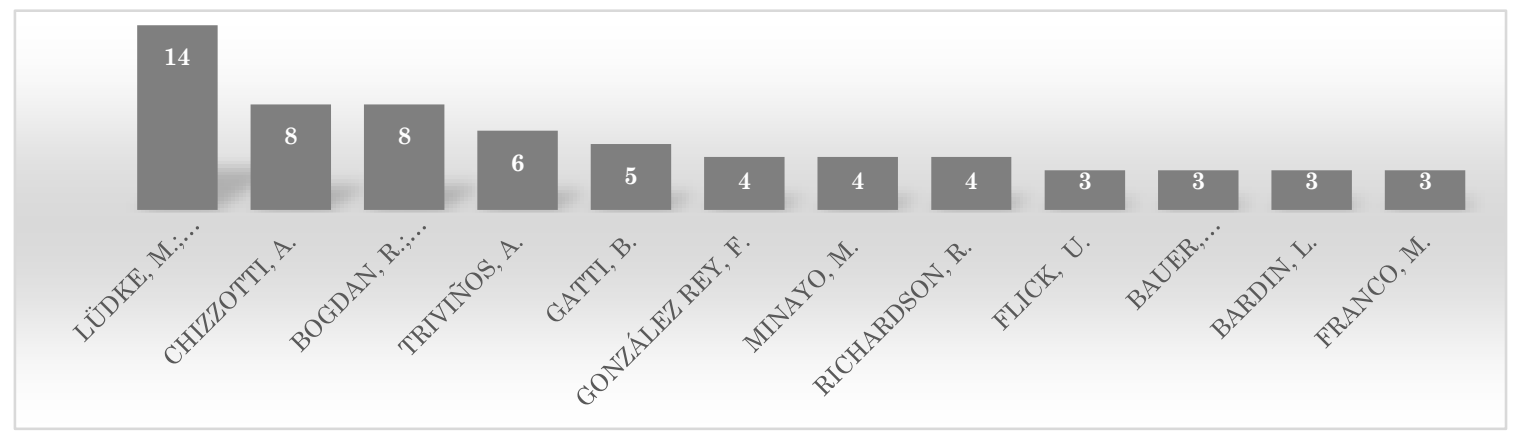

Fonte: dados da pesquisa REDECENTRO (SANTOS; SILVA, 2018)

Dos autores mais citados, Lüdke e André (1986) aparecem em primeiro lugar em 30\% da produção analisada; Bogdan e Biklen (1994), ao lado de Chizzotti (1991; 2003), aparecem em segundo lugar, com 17\%. Triviños (1987) fica em terceiro, com $13 \%$. O fato de autores de base fenomenológica estarem no topo dos mais citados, enquanto a maioria das T/D são de método MHD, leva a questionar a coerência teórico-metodológica nessas produções (vide TABELA 2).

TABELA 2. Identificação explicita ou não em relação ao método

\begin{tabular}{|c|c|c|c|c|c|c|c|}
\hline & $\begin{array}{c}\text { MÉTODO } \\
\text { MHD }\end{array}$ & \multicolumn{2}{|c|}{ MÉTODO FENOMENOLÓGICO } & \multicolumn{2}{|c|}{$\begin{array}{c}\text { MÉTODO } \\
\text { POSITIVISTA }\end{array}$} & $\begin{array}{l}\text { MÉTODO NÃO } \\
\text { IDENTIFICADO }\end{array}$ & $\begin{array}{c}\text { OUTRA } \\
\text { RESPOSTA }\end{array}$ \\
\hline Explicitado & $\begin{array}{c}\text { Não } \\
\text { explicitado, } \\
\text { mas } \\
\text { identificado }\end{array}$ & Explicitado & $\begin{array}{c}\text { Não } \\
\text { explicitado, } \\
\text { mas } \\
\text { identificado }\end{array}$ & Explicitado & $\begin{array}{c}\text { Não } \\
\text { explicitado, } \\
\text { mas } \\
\text { identificado }\end{array}$ & & \\
\hline 14 & 19 & 1 & 4 & 0 & 1 & 3 & 5 \\
\hline \multicolumn{2}{|r|}{33} & & 5 & & 1 & 3 & 4 \\
\hline \multicolumn{8}{|c|}{ Total 46} \\
\hline
\end{tabular}

Fonte: dados da pesquisa REDECENTRO (SANTOS; SILVA, 2018) 
Essa tabela mostra que 33 das 46 obras analisadas fazem referência ao MHD, que representa 71,74\%; nesse conjunto 14 explicitam claramente e 19 não. Mas, nesse caso pôde ser identificado mediante leitura. O método fenomenológico é citado em 5 obras que representa 10,87\% dos trabalhos; desse montante, 1 o expressa visivelmente, 4 não - porém, pode ser distinguido. Do total dos estudos analisados somente 1 foi identificado com análise positivista, 3 não foi possível distinguir o método usado; em 4 houve respostas distintas referentes a outros tipos de métodos.

Os dados aqui apresentados revelam: i) pouca acuidade sobre a abordagem de pesquisa; ii) carência de estudos teórico-metodológicos como parte da produção de conhecimento; iii) falta de coerência entre os referenciais utilizados de abordagem qualitativa de base fenomenológica em pesquisas que se caracterizam como materialista histórico-dialética. Diante de dados como esses, cujo mapeamento se tornou possível mediante uma pesquisa colaborativa, a REDECENTRO vem propiciando uma práxis formativa de orientadores e orientandos, professores e pesquisadores cada vez mais exigentes quanto às escolhas, às fundamentações e às coerências teórico-metodológicas na construção do conhecimento. Nesse contexto, encontram-se as análises a seguir.

\section{Fundamentos teóricos da abordagem qualitativa de pesquisa.}

Mediante o mapeamento dos teóricos sobre enfoque qualitativo trabalhado nas T/D e a análise de excertos do desenvolvimento dessas pesquisas, propusemos uma leitura de aprofundamento dos mesmos autores para que futuros pesquisadores possam selecionar leituras e se deterem em fundamentações coerentes com suas opções metodológicas. Uma base de fundamentação metodológica é essencial à instrumentalização no processo de construir caminhos investigativos, cuja consciência daquele que investiga favorece assumir uma maneira de perceber, entender e analisar a realidade. 
A obra mais referida - Pesquisa em educação: abordagem qualitativa —, Lüdke e André (1986, p. XI) propõem "contribuir para o desenvolvimento dos recursos metodológicos da pesquisa em educação". As autoras foram pioneiras na abordagem sobre o tema no Brasil, nos anos 80. Naquele momento, ocorria uma transição de paradigmas na pesquisa em educação: da pesquisa experimental positivista na área da psicologia à pesquisa interpretativa no campo das ciências sociais. A linguagem e as orientações procedimentais fazem do livro uma obra útil para iniciantes na pesquisa em educação o que parece justificar a predominância prevalente à obra delas, que traz o debate e orientações metodológicas.

Do ponto de vista qualitativo, a obra aponta o surgimento de tipos de pesquisa na busca de resultados mais eficientes para resolver problemas do que hoje denominamos de educação básica. As autoras elencam as pesquisas do tipo participante, emancipatório, pesquisa-ação, etnográfico e estudo de caso. No entanto, se detêm mais nas características das duas últimas. E ainda expõem orientações sobre instrumentos de coleta e análise de dados em procedimentos da observação participante, da entrevista e da análise documental como práticas sistematizadas no enfrentamento de críticas à adequação e a problemas de rigor científico.

Em que pese a importância do livro de Lüdke e André (1986) como introdução à ideia de pesquisa qualitativa, é importante estar ciente de que se trata de uma concepção fenomenológica. Embora as autoras não explicitem essa relação, ela está evidenciada quando vinculam "pesquisa qualitativa" às cinco características apresentadas por Bogdan e Biklen (1994), cujas definições são fenomenológicas.

Dito isso, na quase totalidade da coletânea analisada, Lüdke e André formam referência-chave. Alguns citam Bogdan e Biklen (1994), ao lado de Triviños (1987) e Chizzotti (1991), dentre outros. O excerto a seguir ilustra tais vinculações teóricas.

$\mathrm{Na}$ formulação do meu projeto de pesquisa, optei por uma abordagem qualitativa cuja referência são Robert Bogdan e Sari Biklen (1998) e Ludke e André (1986). Considero que meu 
trabalho atende à descrição que fazem esses autores de uma investigação qualitativa. (Instituição 2, ficha 11).

Mesmo assim, há uma superficialidade da inserção do assunto que favorece a falta de coerência entre os referencias da abordagem e do método; a assunção equivocada de abordagem como sinônimos de tipo de pesquisa etnográfica; o não entendimento das características da abordagem qualitativa como potencialidade aplicada à pesquisa, corroborando na construção de caminhos investigativos.

As características dessa abordagem são definidas a priori por Bogdan e Biklen (1994), que aparecem em segunda posição dentre os autores mais citados, sem que façam referência a uma concepção na perspectiva do método fenomenológico. Cabe ressaltar que apesar de estarem na segunda posição de autores mais referenciados, apenas uma obra, do corpus em análise, foi explicita uma abordagem articulada ao método fenomenológico.

No caso de uma referência coerente com a fenomenologia (Instituição 4, ficha 35), o autor a caracteriza como abordagem de cunho interpretativo, em que os pesquisadores se interessam mais pelo processo investigativo do que pelos resultados. Até podem trabalhar com dados quantitativos, mas são expressos em análises qualitativas. Mas a obra de Bogdan e Biklen, é utilizada incoerentemente como referência, em diversas dissertações de base MHD, como podem ser destacadas.

Optei por uma abordagem qualitativa, cuja referência são Robert Bogdan e Sari Biklen (1998) e Ludke e André (1986) [...]. Nessa abordagem, os pesquisadores frequentam os locais de estudo, porque se preocupam com o contexto, e os dados são descritivos e recolhidos pelo próprio investigador, que se interessa mais pelo processo que pelos resultados ou produtos; os investigadores qualitativos tendem analisar seus dados de forma indutiva. (Instituição 2, ficha 11).

A leitura dessas passagens mostra características inegáveis de uma pesquisa qualitativa, se não fosse a incoerência teórico-metodológica na perspectiva do método trabalhado na construção do conhecimento. Ao identificar essas incoerências, a Rede promove diversos debates, embasados 
em leituras sistematizadas e análises, na busca por uma conscientização, primeira, dos próprios integrantes no aprimoramento de suas produções.

Nossas reflexões nos levam a compreensão do fato da obra de Lüdke e André ser a mais citada nas pesquisas sobre professores; afinal, explora a abordagem qualitativa em pesquisa sobre educação com clareza e didatismo ao expor temas como tipos e procedimentos de pesquisa. Mas cabe indagar, no contexto da produção até 2014: em trinta anos não houve avanços na epistemologia da abordagem qualitativa? Por que uma obra escrita com objetivos introdutórios, num momento incipiente sobre a temática no Brasil, continua a ser a obra mais citada em pesquisas sobre o professor? Que sentido a obra embasada numa abordagem qualitativa fenomenológica tem num corpus cuja produção se vincula predominantemente ao MHD?

Ao lado de Bogdan e Biklen (1994), a obra de Chizotti (1991) aparece em segundo lugar. $\mathrm{O}$ Autor em vez de assumir dada perspectiva epistemológica e teórico-metodológica, em seu livro faz um mapeamento que ajuda - embora com incipiência — o iniciante a se situar na dimensão das escolhas para que possa fazer as suas e buscar aprofundamento na literatura. Sua obra surge das experiências e demandas de informações básicas e panorâmicas para fundamentar trabalhos de pós-graduação em educação. $\mathrm{O}$ conteúdo oferece uma visão geral da pesquisa experimental e da qualitativa; aponta uma bibliografia teórico-metodológica brasileira e estrangeira de meados dos anos 70 aos anos 90; enfim, faz recomendações úteis quanto à sistematização e construção de suas pesquisas.

Chizzotti (1991) caracterizou o estado de coisas da pesquisa e as tendências consideradas conflitantes até então. Em suas palavras,

Um paradigma que se caracteriza pela adoção de uma estratégia de pesquisa modelada pelas ciências naturais e baseada na observação empírica para explicar os fatos e fazer previsões, e outro, que advoga uma lógica própria para os estudos dos fenômenos humanos e sociais, procurando significações dos fatos no contexto concreto em que ocorrem (CHIZZOTTI, 1991, p. 12). 
O primeiro paradigma se fundamenta no positivismo; o segundo, em duas vertentes distintas: a fenomenológica e a dialética; das quais Chizzotti apresenta características e mapeamento teórico da pesquisa qualitativa, mediante uma apresentação que inclui tópicos como: pressupostos, orientações filosóficas, coleta de dados qualitativos, observação participante, entrevista, história de vida, análise de conteúdo, pesquisa-ação e pesquisaintervenção, estudo de caso, etapas da pesquisa qualitativa e outros. Ele ainda discorre sobre documentação. $\mathrm{O}$ texto faz uma introdução a fontes como as bibliotecas, os arquivos, o centro de documentação bibliográfica, os produtos documentários, a bibliografia.

Ao recorrerem a Chizzotti, os pós-graduandos já buscam uma maior compreensão da abordagem qualitativa, de suas características e implicações no processo investigativo.

'[...] na pesquisa qualitativa, todas as pessoas que dela participam são reconhecidas como sujeitos que elaboram conhecimentos e produzem práticas [...] elas têm um conhecimento prático, de senso comum e representações relativamente elaboradas que formam uma concepção de vida e orientam as suas ações individuais (CHIZZOTTI, 2005, p, 83) ${ }^{8}$.' (Instituição 1, ficha 8)

Segundo Chizzotti (1995), a abordagem qualitativa revela uma relação dinâmica entre o investigador e o sujeitoinvestigado. Há também uma interdependência constante entre o sujeito e o objeto, na qual o conhecimento não se limita a dados isolados. $\mathrm{O}$ sujeito-investigador não é alheio e neutro ao que está sendo desenvolvido, ele é parte integrante do processo de conhecimento e interpreta os fenômenos, atribuindo-lhes um significado. (Instituição 3, ficha 28)

Nos exemplos, ilustrados acima, destacam a participação direta dos sujeitos investigados com seus conhecimentos práticos; a relação do pesquisador com o objeto investigado; o contexto histórico e transformações da abordagem qualitativa nas pesquisas sobre o fenômeno social com recorrência as cinco características apresentadas por Bogdan e Biklen (1994). Logo, a utilização dessas características, fundamentadas

\footnotetext{
${ }^{8}$ CHIZZOTTI, Antonio. A pesquisa qualitativa em ciências humanas e sociais: evolução e desafios. Revista Portuguesa de Educação. Braga/Portugal, v. 16, n. 2, p. 221-236, 2005.
} 
no método fenomenológico, em pesquisas que seguem o ponto de vista do MHD suscita questionamentos sobre coerência metodológica. O que aponta uma necessidade urgente de aprofundamento das distinções das características quanto ao método, exploradas por Trivinõs (1987) e Chizzotti (1991) de maneira incipiente.

Nesse sentido procuramos responder a seguir: o que diferencia a abordagem qualitativa numa pesquisa de método fenomenológico em relação ao materialista histórico-dialético? Quais são os referenciais teóricos da abordagem qualitativa coerentes com cada um desses dois métodos? Parecenos que as diferenças estão no método e na relação que este estabelece entre sujeito e o objeto de estudo; isto é, no modo de coletar e/ou construir dados, analisá-los e/ou se interpretá-los e abordar o fenômeno investigado. Tal relação impacta diretamente no tipo de pesquisa e procedimentos para a busca e sistematização de dados.

\section{Abordagem qualitativa, fenomenologia e materialismo histórico dialético: diferenças}

A compreensão da diferença entre a visão qualitativa fenomenológica e a materialista histórica dialética ainda desafia a literatura, que se ocupa, sobretudo, do processo de diferenciar o enfoque qualitativo do quantitativo (CHIZZOTTI, 1991; ALVES-MAZZOTTI; GEWANDSZNAJDER 1998; SAMPIERI, 2013).

Em suas origens, a abordagem qualitativa foi concebida no ponto de vista do método fenomenológico aplicado em pesquisas do tipo etnográficoantropológicas (BOGDAN; BIKLEN, 1994). Depois, foi apropriada por pesquisas de correntes muito diferentes, mas contrárias ao método e às técnicas de estudos experimentais positivistas. Assim, convém limitar esta exposição às características de fundamentação da construção do conhecimento na perspectiva fenomenológica e na dialética (CHIZZOTTI, 1991; TRIVIÑOS, 1987). Mesmo com as formas variadas de abordagem 
qualitativa, reiteramos Bogdan e Biklen (1994, p. 54): “todas partilham, até certo ponto, o objetivo de compreender os sujeitos com base nos seus pontos de vista". A advertência é que um construto da investigação exige do investigador ciência de questões teóricas e metodológicas.

Triviños (1987) - terceiro autor mais citado no corpus em análise mapeou as diferenças da abordagem qualitativa vinculada ao método fenomenológico e ao MHD. Sua obra mostra ser uma referência inicial para quem procura coerência em suas escolhas metodológicas na construção do conhecimento. À luz de apropriações das características da abordagem qualitativa em Bogdan e Biklen, será traçado um paralelo ainda introdutório para esclarecimentos e distinções.

$\left.1^{a}\right)$ "Na investigação qualitativa a fonte direta de dados é o ambiente natural, constituindo o investigador o instrumento principal" (BOGDAN; BIKLEN, 1994, p. 47). Ao partir do estudo de sujeitos, a primeira característica aí apontada aglutina três aspectos. O estudo direto da fonte de dados; o ambiente natural vinculado ao contexto em que emergem as informações; o investigador como quem está imerso no campo de produção de informação.

Fonte direta de dados. Evidenciada em um extrato de dissertação/tese, essa característica implica estudar os sujeitos como fonte direta de dados (orais, documentais e visuais). Parte-se do princípio de que possuem conhecimentos cuja compreensão se torna relevante à pesquisa. Mas se explicita apenas que se trabalha com a fonte direta, como neste fragmento:

A pesquisa apresentada é de cunho qualitativo. Em virtude disto [...], lócus desta pesquisa, é considerado ambiente natural e fonte direta para a coleta de dados, o que, por sua vez, ocorreu através de fontes documentais e orais. (Instituição 4, ficha 41).

Tal inserção não abarca as nuances e demandas qualitativas no processo investigativo. É preciso compreender, aprender a ir a campo; explorar o sentido da fonte direta de dados; adentrar esse universo para trazer à tona informações e trabalhá-las. Vinculado ao método, o modo 
como o pesquisador concebe o conhecimento - apreensão e construção vai distinguir o quê e o como buscar informações e transformá-las em textos sistematizados. Sem essa definição, fica difícil construir um caminho de pesquisa coerente.

Em um estudo fenomenológico, o conhecimento se vincula à experiência de vida dos sujeitos (pesquisador e informante). Um estudo dialético pressupõe que os sujeitos que compõem o universo da pesquisa têm um conhecimento prático, do senso comum, da vivência cotidiana; e necessariamente não refletem um conhecimento crítico, cujas contradições entre informação e realidade constituem desafio de apreensão ao pesquisador (KOSIK, 1976). Com efeito, o objeto de pesquisa encontra-se nas relações sociais, culturais, históricas, econômicas, tecnológicas, estéticas, éticas, étnico-raciais, dentre outras presentes nas comunidades de indivíduos. Ele necessita ser lapidado de um estado abrangente, comum a todos, para algo mais próximo, com sentido, que diz respeito e interrelaciona com os anseios do próprio pesquisador de querer solucionar uma determinada situação problematizada.

Chizzotti (1991) se refere a essas características, mas não explicita uma afiliação metodológica. Antes, procura estabelecer pontos comparativos de características entre abordagem qualitativa de orientação filosófica fenomenológica e dialética; mas, ao se atentar às suas características na perspectiva da delimitação e formulação do problema, do pesquisador, dos pesquisados e das técnicas, essa distinção se dissipa ao incluir traços coincidentes.

Ambiente natural. Os investigadores qualitativos frequentam os lócus da investigação porque entendem que as ações podem ser compreendidas mais a fundo, com mais detalhe e mais nuance quando observadas em seu ambiente habitual de ocorrência. "Os locais têm de ser entendidos no contexto da história das instituições a que pertencem [...]. Para o investigador qualitativo divorciar o acto, a palavra, ou gesto do seu contexto é perder de vista o significado" (BOGDAN; BIKLEN, 1994, p. 48). 
Se assim o for - se o ambiente se torna importante na configuração do sujeito -, então cabe dizer que para Triviños (1987) a concepção de meio na fenomenologia e na dialética é distinta. $\mathrm{Na}$ primeira, circunscreve-se à cultura em dada realidade; na segunda, é compreendido como realidade mais complexa vinculada à infraestrutura e à superestrutura, constituintes da sociedade em geral.

Investigadores que apoiam o interacionismo simbólico da escola de Chicago - de base fenomenológica - compreendem que a "pesquisa não pode ser o produto de um observador postado fora das significações que os indivíduos atribuem aos seus atos; deve, pelo contrário, ser o desvelamento do sentido social que os indivíduos constroem em suas interações cotidianas" (CHIZZOTTI, 1991, p. 80). Para a fenomenologia, a apreensão dos sentidos das informações implica imersão do investigador no cotidiano, no contexto, num tempo mais extenso de observação direta; mas a familiaridade com as coisas tangíveis vela os fenômenos, como adverte Chizzotti (1991, p. 80): é "necessário ir além das manifestações imediatas para captá-los e desvelar o sentido oculto das impressões imediatas. O sujeito precisa ultrapassar as aparências para alcançar a essência dos fenômenos". O contexto é concebido no tempo presente.

Já o investigador que se apoia na dialética sem desconsiderar a importância do ambiente natural do objeto de investigação de forma recorrente procura apreender o contexto lançando mão de outras fontes complementares, tais como documentos e imagens. Não se limita a compreender o contexto do objeto investigado no tempo presente. Pensa historicamente e comunica-se com o entorno social. Por isso, há necessidade de compreender a contradição, a alienação, a luta de classe, a totalidade escondida no próprio fenômeno analisado. A passagem a seguir ilustra essa reflexão; é citação que um autor fez em seu trabalho (Instituição 5, ficha 52)

Realizar uma pesquisa na abordagem qualitativa tende para o estudo de questões delimitadas, locais, de forma a apreender os sujeitos no ambiente natural em que vivem, 
nas suas interações interpessoais e sociais, nas quais tecem os significados e constroem a realidade. Assim, a abordagem qualitativa vem permitindo análises contextualizadas dos fenômenos da realidade social, do conhecimento e do ser humano em sua totalidade (SOUZA; MAGALHÃES; GUIMARÃES, 2011) ${ }^{9}$.

Investigador como instrumento principal. Na pesquisa fenomenológica, o investigador é o agente da apreensão e coleta de informação. Ele se detém no vivido e nas significações subjetivas dos atores sociais. Na pesquisa dialética, o pesquisador "valoriza a contradição dinâmica do fato observado e a atividade criadora do sujeito que observa, as oposições contraditórias entre o todo e a parte e os vínculos do saber e do agir com a vida social dos homens"; nesse caso, "o pesquisador é um ativo descobridor do significado das ações e das relações que ocultam nas estruturas sociais" (CHIZZOTTI, 1991, p. 80).

$2^{a}$ ) “A investigação qualitativa é descritiva" (BOGDAN; BIKLEN, 1994, p. 48). Diferentemente da descrição de dados quantitativos, cabe ao investigador a apropriação dos dados via fonte verbal, escrita ou imagética; ele tem de descrever as informações em minúcia e entender que "nada é trivial, que tudo tem potencial para constituir uma pista que nos permita estabelecer uma compreensão mais esclarecedora do nosso objeto de estudo" (BOGDAN; BIKLEN, 1994, p. 49). A descrição é procedimento de recolha de informações. O investigador busca evitar que lhe escape detalhes e pistas para novas buscas; mas não se ocupa nem se preocupa com quantificar e apresentar números - como em pesquisas de feição positivista.

$\mathrm{Na}$ fenomenologia, a descrição assume característica predominante na recolha de informações que constituem dados e o relatório final da pesquisa. A descrição é interpretativa e dialoga com bases teóricas e a visão do investigador. Não busca explicar nem analisar, mas refletir, interpretar. A intencionalidade da consciência e a experiência do sujeito (TRIVINOS, 1987), é base da interpretação dos fenômenos. Já para o MHD,

\footnotetext{
${ }^{9}$ SOUZA, R. C.C.; MAGALÃES, S. O.; GUIMARÃES, W. S. Método e metodologia na pesquisa sobre professore(s). In: SOUZA, R. C.C.; MAGALÃES, S. O. (org.) Pesquisa sobre professores(as): Métodos, tipos de pesquisas, temas, ideário pedagógico e referenciais. Goiânia: PUC/Goiás, 2011. p. 37- 68.
} 
A pesquisa qualitativa de tipo histórico-estrutural, dialética parte também da descrição que intenta captar não só a aparência do fenômeno, como também sua essência. Busca, porém, as causas da existência de lei procurando explicar sua origem, suas relações, suas mudanças e se esforça por intuir as conseqüências que terão para a vida humana (TRIVIÑOS, 1987, p. 129).

A produção de dados caracteriza a perspectiva dialética de descrição, mas procura desenvolver um processo de análise a partir de indicadores e da construção de categorias.

$3^{a}$ ) "Os investigadores interessam-se mais pelo processo do que simplesmente pelos resultados dos produtos" (BOGDAN; BIKLEN, 1994, p. 48). Os investigadores se atêm ao como ocorrem as negociações de significados, à construção de uma concepção que se torna senso comum, à história que antecede, influencia e se faz essencial para compreender determinado fenômeno, aos estudos que focam mais no modo como os participantes da pesquisa constroem significados e dão sentido a um fenômeno com base na percepção de si, do outro e do meio.

De fato, fenomenologia e MHD se propõem a estudar os fenômenos, porém, a pesquisa fenomenológica segue uma interpretação a-histórica, limitada a circunstâncias imediatas que envolvem o fenômeno, enquanto a investigação dialética histórica procura apreender o fenômeno em sua feição aparente - início da análise - e em sua feição não aparente: suas relações com forças decisivas e responsáveis pelo fenômeno histórico.

$4^{\mathrm{a}}$ ) "Os investigadores qualitativos tendem a analisar os seus dados de forma indutiva” (BOGDAN; BIKLEN, 1994, p. 50). Aspecto só anunciado nos extratos das T/D, os dados coletados não se destinam a confirmar ou refutar hipóteses a priori; servem para uma análise cuja abstração parte de uma totalidade de informações que vão se estreitando - feito um funil - em indicadores específicos e categoriais que surgem dos dados da pesquisa de campo.

Ambos os tipos de pesquisa qualitativa partem do fenômeno social sobre o qual se inicia diretamente a análise. Existem, porém, diferenças fundamentais. A pesquisa qualitativa fenomenológica não tem hipóteses para 
verificar empiricamente; "isto significava a presença de uma teoria, toda uma concepção delimitada a priori. Os significados, a interpretação, surgem da percepção do fenômeno visto num contexto. Assim, chega-se ao nível de abstração, ao conceito”, numa análise indutiva (TRIVIÑS, 1987, p. 129).

$\mathrm{Na}$ pesquisa qualitativa com raízes no materialismo histórico dialético,

[...] o fenômeno tem sua própria realidade fora da consciência. Ele é real, concreto e, como tal, é estudado. Isto significa enfocá-lo indutivamente. Porém, ao mesmo tempo, ao descobrir sua aparência e essência, está-se avaliando um suporte teórico, que atua dedutivamente, que só alcança a validade à luz da prática social (TRIVIÑOS, 1987, p. 129).

Logo, segundo esse método, a análise comporta uma abordagem indutivo-dedutiva numa investigação da realidade concreta do fenômeno.

Isto significa estabelecer os aspectos essenciais do fenômeno, seu fundamento, sua realidade e possibilidades, seu conteúdo e sua forma, o que nele é singular e geral, o necessário e o contingente etc. Para atingir a realidade concreta do fenômeno, realiza-se um estudo das informações, observações, experimentos etc. A descrição, a classificação, a análise, a síntese, a busca da regularidade estatística que determina com precisão o concreto do objeto, as inferências (indutivas e dedutivas), a experimentação, a verificação das hipóteses etc. são momentos da investigação que tendem a estabelecer a realidade concreta do fenômeno (TRIVINOS, 1987, p. 74).

$5^{\text {a) }}$ "O significado é de importância vital na abordagem qualitativa" (BOGDAN; BIKLEN, 1994, p. 50). É a característica mais recorrente no corpus em análise. Inclui-se até nos títulos das teses e dissertações - não explicitados em sua totalidade aqui por uma razão ética, ou seja, para evitar identificação de autoria. Mas convém ilustrar pelo corpus das fichas da REDECENTRO em análise (2018): “O significado do aprender e do ensinar...”, "Sentidos e significados da docência...”, “... significados e sentidos do cotidiano escolar...", “... o significado pedagógico...”, "Novos olhares, novos significados...”. Eis algumas passagens no conjunto de fragmentos analisados: 
A escolha por essa abordagem [qualitativa] possibilitou maior interação entre o pesquisador e o pesquisado [...] ambos se tornaram canais mediadores que possibilitaram colocar em questão os lugares desses agentes no processo de descrever e interpretar os componentes de um sistema complexo de significados tanto para o sujeito da pesquisa como para o pesquisador (BRANDÃO. 2003, p. 186) ${ }^{10}$. (Instituição 2, ficha 13).

A pesquisa qualitativa numa perspectiva sócio-histórica, que tem o materialismo-dialético como referência, deve expressar em seu arcabouço conceitual as marcas de sua filiação dialética. É com essas marcas que assumimos diferentes procedimentos metodológicos de investigação para encontrar o sentido dos fenômenos, assim como interpretar os significados que lhes dão os sujeitos [...] (SOUZA; MAGALHÃES; GUIMARÃES, 2009; 2010). (Instituição 5, ficha 52).

Desses fragmentos, o primeiro traz a apreensão do significado na perspectiva da fenomenologia; os demais estão contextualizados numa produção segundo o MHD, mas não apresentam diferenciação; mesmo quando houve esforço em descrever o significado numa abordagem qualitativa vinculada ao método - vide o caso identificado da instituição 5, ficha 52.

$\mathrm{Na}$ produção em análise, a caracterização da abordagem qualitativa parece estar, direta ou indiretamente, incrustada no ideário de Bogdan e Biklen (1994), seja pelas referências a Lüdke e André (1986) ou por não ultrapassar a concepção por elas trabalhada. Como característica apresentada Bogdan e Biklen (1994, p. 50), o significado é "vital na abordagem qualitativa”.

O fato de os pesquisadores qualitativos estabelecerem "estratégias e procedimentos" que permitem a eles considerar "as experiências do ponto de vista do informador" (BOGDAN; BIKLEN, 1994, p. 51) reflete uma espécie de diálogo entre investigador e respectivos sujeitos. O significado é apreendido com ênfase na subjetividade. Mas necessariamente não nega a realidade "exterior" numa perspectiva fenomenológica. A realidade só se dá a conhecer aos humanos da forma

\footnotetext{
${ }^{10}$ BRANDÃO, Carlos R. A pergunta a várias mãos: a experiência da pesquisa no trabalho do educador. São Paulo: Cortez, 2003.
} 
como é percebida e entendida. "Vivemos na imaginação, contexto bem mais simbólico do que concreto" (BOGDAN; BIKLEN, 1994, p. 51).

Eis um dos distanciamentos ao se trabalhar com o significado na perspectiva do materialismo histórico dialético, quando se busca apreendêlo num contexto histórico, material e concreto. $\mathrm{Na}$ perspectiva fenomenológica, a apreensão do significado ainda traz nuances diferentes em suas correntes: interação simbólica, cultura e etnometodologia. A base da abordagem da interação simbólica contém a concepção "de que a experiência humana é mediada pela interpretação. Nem os objetos, nem as pessoas, situações ou acontecimentos são dotados de significado próprio: ao invés, o significado é-lhe atribuído" (BOGDAN; BIKLEN, 1994, p. 56). O significado é construído mediante interações, definições e partilhas de perspectiva, é sujeito a negociações. Entende-se "que não são as regras, regulamentos, normas ou o que quer que seja crucial para a compreensão do comportamento, mas sim o modo como estes são definidos e utilizados em situações específicas" (BOGDAN; BIKLEN, 1994, p. 56).

Nos estudos sobre cultura, por sua vez, sua descrição — ou aspectos dela - designa-se por etnografia, assim como os estudos dos sinais da língua cabem à semiótica. $\mathrm{O}$ etnógrafo se preocupa com representações. Recorre ao recurso do "conceito de cultura, independentemente da sua definição específica" como "principal instrumento organizativo e conceptual de interpretação de dados que caracteriza a etnografia" (BOGDAN; BIKLEN, 1994, p. 59). A etnometodologia se refere ao estudo do modo como os indivíduos constroem e compreendem suas vidas cotidianas.

Numa abordagem qualitativa MHD, os estudos culturais se diferem da perspectiva fenomenológica porque "rejeitam a noção de que o mundo é "susceptível de ser conhecido diretamente"; antes, "as relações sociais são influenciadas por relações de poder que devem ser entendidas mediante a análise e interpretação que fazem das suas próprias situações” (BOGDAN; BIKLEN, 1994, p. 61). Todas as características e distinções da abordagem qualitativa aqui apresentada estão vinculadas aos métodos, por isso, sua 
utilização sempre demandarão aprofundamentos teóricos e melhor compreensão das mesmas para que se efetive uma práxis investigativa.

\section{Considerações finais}

Pesquisadores como Gatti e André (2010) têm se esforçado na análise da produção intelectual acadêmica sobre educação no Brasil. A eles se somam os pesquisadores da REDECENTRO há mais de uma década. A pesquisa colaborativa e em rede desenvolvida tem auxiliado a manter um processo formativo de seus membros, além da convivência coletiva e cooperativa. Gradativamente, essa perspectiva de trabalho coletivo tem consolidado um espaço de "socialização de dúvidas e experiências, além de influenciar o sentido colaborativo-crítico na realização das investigações com mais segurança e autonomia" (MAGALHÃES, 2021, s/p).

Na especificidade da análise aqui apresentada, buscamos apoiar os avanços na qualidade da produção de conhecimento na área da educação, e para tanto, relatamos as dificuldades metodológicas e de fundamentação nas produções analisadas, para com isso nortear estudos que apoiem a formação de novos pesquisadores.

Embora pareça inesgotável a demanda de análises e discussões úteis para ampliar os processos formativos, os modos de investigação e suas fundamentações, parece-nos que o trabalho colaborativo, a troca de experiência potencializa a práxis investigativa. Parafraseando Bogdan e Biklen (1994) em outro contexto de discussão, reiteramos que buscar a fundamentação teórico-metodológica não é desenvolvê-la como se o objeto de estudo fosse a metodologia, numa atitude de quase inversão de valores, ou seja, de objetos. Antes, é embasar os caminhos filosóficos da construção do conhecimento e de procedimentos necessários à construção de pesquisas sistematizadas (GATTI; ANDRÉ, 2010), o que seria o mesmo que dizer que a pesquisa colaborativa pode iluminar práticas investigativas com maior rigor 
epistemológico - isso envolve desde a escolha do método, metodologias, abordagens de pesquisas, até a análise, e apresentação dos resultados obtidos.

Nossos resultados, no que se refere às pesquisas de abordagem qualitativa, mostra que embora todos os pesquisadores insinuem conhecimento sobre essa abordagem, eles ainda requerem um movimento permanente de formação adequada para a construção e reconstrução do objeto de estudo; ou seja, conhecimentos teórico-metodológicos consistentes. Afinal, a julgar pelos dados de T/D analisadas aqui, podemos destacar e assumir a importância do conhecimento metodológico em relação ao objeto de estudo definido pelo pós-graduando, esse domínio ainda, parece ser uma carência na produção acadêmica de pesquisas sobre o professor no Centro-Oeste. Conhecer, entender e construir os caminhos metodológicos implica enfrentar as carências de formação de quem busca a pesquisa como meio de aprimoramento, assim como aproveitar as potencialidades e anular os limites do percurso investigativo escolhido. A conscientização e a atitude crítico-reflexiva se impõem como condições para construir conhecimentos sistematizados.

\section{Referências}

ALVES-MAZZOTTI, A. J.; GEWANDSZNAJDER, F. O método nas ciências naturais e sociais: pesquisa quantitativa e qualitativa. São Paulo: Pioneira, 1998.

BOGDAN, R.; BIKLEN, S. K. Investigação qualitativa em educação. Porto: editora Porto, 1994.

CHIZZOTTI, A. Pesquisa em ciências humanas e sociais. São Paulo: Cortez, 1991.

CHIZZOTTI, A. A pesquisa qualitativa em ciências humanas e sociais: evolução e desafios. Revista Portuguesa de Educação, v. 16, n. 2, p. 221-36, 2003.

FRANCO, M. E.; MOROSINI, M. C. (Orgs.). Redes acadêmicas e produção do conhecimento em educação superior. Brasília, INEP, 2001.

GAMBOA, S. S; SANTOS FILHO, J. C. Pesquisa educacional: quantidadequalidade. 8. ed. São Paulo: Cortez, 2013. 
GATTI, B.; ANDRÉ, M. A relevância dos métodos de pesquisa qualitativa em Educação no Brasil. In: WELLER, W.; PFAFF, N. (Org.). Metodologias da pesquisa qualitativa em educação. Petrópolis: Vozes, 2010.

KOSIK, K. Dialética do concreto. 10. ed. Rio de Janeiro: Paz e Terra, 1976.

LÜDKE, M.; ANDRÉ, M. Pesquisa em educação: abordagens qualitativas. São Paulo: EPU, 1986.

MAGALHAES, S. M. O.; SOUZA, R. C. C. R. (org.). Epistemologia da práxis e epistemologia da prática: repercussões na produção de conhecimentos sobre professores: repercussões na produção do conhecimento sobre professores. Campinas, SP, Mercado das Letras, 2018.

MAGALHAES, S. M. O. Entrevista: Maria Isabel da Cunha. Diálogos sobre a Pesquisa Colaborativa e em Rede: "o desafio de construir uma caminhada coletiva". Ensino em Revista. 2021 (Prelo).

MAGALHAES, S. M. O.; SOUZA, T. Z.; ARGUELLO, S.B. Investigação colaborativa e o processo de formação de redes de conhecimento. Ensino em Revista. 2021 (Prelo).

REDECENTRO. Fonte documental: 77 fichas de dissertações e teses de seis instituições do Centro-Oeste. REDECENTRO, 2018.

SAMPIERI, F. R. H. Metodologia de pesquisa. 5 ed. Porto Alegre: Penso, 2013.

SANTOS, A. N. F; SILVA, E.C. Dados da pesquisa REDECENTRO (fonte documental). Uberlândia, 2018.

SILVA; E. C.; SANTOS, A. N. F. O que as dissertações e teses sobre professores (as) defendidas no Programa de pós-graduação em educação da UFU revelam? In: SOUZA, R.C. C.; MAGALHÃES, S. M. O.; QUIEROZ, V. R. F. Pesquisas sobre professores(as) no Centro-Oeste: dimensões teóricas e metodológicas. Goiânia: IFG, 2017.

TRIVIÑOS, A. N. S. Introdução à pesquisa em ciências sociais: a pesquisa qualitativa em educação. São Paulo: Atlas, 1987. 